\title{
KNN BASED CLASSIFICATION OF DIGITAL MODULATED SIGNALS
}

\author{
ASAd HuSSAIN ${ }^{1,2}$, SAJJAd AHMEd GHAURI ${ }^{* 3}$, M. FARHAN SOHAIL ${ }^{1}$, \\ SHERAZ A. KHAN ${ }^{1}$ AND IJAZ MANSOOR QURESHI ${ }^{4}$ \\ ${ }^{I}$ National University of Modern Languages, Islamabad 44000, Pakistan. \\ ${ }^{2}$ ISRA University, Islamabad 44000, Pakistan. \\ ${ }^{3}$ International Islamic University, Islamabad 44000, Pakistan. \\ ${ }^{4}$ AIR University, Islamabad 44000, Pakistan. \\ *corresponding author: sajjad.ghauri@iiu.edu.pk \\ (Received: $6^{\text {th }}$ Mar. 2016; Accepted: 20 Jun. 2016; Published on-line: $30^{\text {th }}$ Nov. 2016)
}

\begin{abstract}
Demodulation process without knowledge of the modulation scheme requires Automatic Modulation Classification (AMC). When the receiver has limited information about the received signal, AMC becomes an essential process. AMC has an important place in many civil and military fields such as modern electronic warfare, interfering source recognition, frequency management, link adaptation, etc. In this paper, we explore the use of $\mathrm{K}$-nearest neighbor $(\mathrm{KNN})$ for modulation classification with different distance measurement methods. Five modulation schemes are used for classification purposes which are Binary Phase Shift Keying (BPSK), Quadrature Phase Shift Keying (QPSK), and Quadrature Amplitude Modulation (QAM) as both 16-QAM and 64-QAM. Higher order cumulants (HOC) are used as an input feature set to the classifier. Simulation results show that the proposed classification method provides better results for the considered modulation formats.
\end{abstract}

ABSTRAK:Proses Demodulation tanpa ilmu mengenai skim modulasi memerlukan Klasifikasi Modulation Automatik (AMC). Apabila penerima mempunyai maklumat yang terhad mengenai signal yang diterima, maka AMC menjadi proses yang penting. AMC adalah penting didalam pelbagai bidang sivil dan ketenteraan seperti peperangan elektronik moden, gangguan di dalam pengiktirafan sumber, pengurusan kekerapan, penyesuaian pautan dan lain-lain. Dalam kertas ini kami meneroka penggunaan jiran Kterdekat (KNN) bagi klasifikasi modulasi dengan kaedah pengukuran jarak yang berbeza. Lima skim modulasi digunakan untuk tujuan mengklasifikasi adalah Penguncian Anjakan Fasa Biner (BPSK), Penguncian Anjakan Fasa Quadrature (QPSK), Quadrature Pemodulatan Amplitud (QAM), 16-QAM dan 64-QAM. Cumulants paras tinggi (HOC) digunakan sebagai set ciri input yang ditetapkan untuk pengelas. Hasil simulasi menunjukkan bahawa cadangan kaedah pengelasan memberi keputusan yang lebih baik untuk format modulasi yang dipertimbangkan.

KEYWORDS:automatic modulation classification (AMC); higher order cummulants (HOC);K-nearest neighbor (KNN); QAM and QPSK

\section{INTRODUCTION}

Automatic modulation classification is a procedure performed at the receiver based on the received signal before demodulation when the modulation format is unknown to the receiver. It plays a key role in various tactical communication applications. It also finds applications in emerging wireless communication systems that employ interference cancelation techniques in order to demodulate and cancel the unknown interfering user's 
signal. In the interference application, the signal's modulation format needs to be classified first. The solution to the problem of AMC strongly relies on one of the two approaches i.e. the likelihood-based (LB) [1,2] and the feature-based (FB) AMC[3, 4].

The LB approach performs AMC-based on the likelihood function of the received signal, by which modulation classification can be formulated as a multiple hypothesis test problem with multiple unknown modulation parameters [5]. The LB-based AMC approach can theoretically reach the optimum solution in the Gaussian condition, but at a cost of computational complexity. Moreover, its performance is affected by model mismatch in the presence of carrier frequency offsets, phase errors, timing errors, and residual channel effects. In contrast, the FB approach is sub-optimal in performance but very feasible in real-time implementation.

The FB-based AMC approach mainly extracts reference features from the received signal and makes decisions from the calculated features based on the theoretical values for different modulation parameters. In brief, the FB approach benefits from lower computational complexity, with better efficiency and less sensitivity to possible model mismatches. In the FB approach, three features are often discussed in the literature: instantaneous information [6,7], wavelet coefficients [8-10] and high-order statistics (HOS) [11-15]. The instantaneous information may include the instantaneous amplitude, phase, or frequency of the incoming signal. These features are the most intuitive ones with less complex implementation. However, they are sensitive to additive noises and the residual channel effects. Moreover, the extraction of instantaneous information relies on thresholds that are set in advance. The wavelet coefficients can be obtained through a Haar wavelet transform by transforming the signal into its wavelet coefficients. Modulation classification with wavelet coefficients has better resistance to the noise at the cost of higher complexity, compared with that with instantaneous information. HOS is a more frequently adopted feature than the previous two, generally including the statistics of moments and cumulants [16-18]. In addition to classification of the modulation types, HOS can distinguish modulation orders with high resistance to the additive white Gaussian noise (AWGN) as well. Furthermore, the multipath channel effects can be easily modeled using the HOS method [19-21].

Most of the previous research work on AMC has focused on the modulation classification techniques in AWGN. Actually, the correctness of modulation classification is seriously degraded subject to the multipath fading effect in wireless channels. The pioneer work by $\mathrm{Wu}$ et al. [20] derived a relationship between the normalized channel coefficients and the normalized fourth-order cumulants. Through their formulation, the classification of the transmitted modulated symbols can be obtained from the normalized fourth-order cumulants of the received signal. The blind channel estimation method using higher-order cumulants was then adopted in [22, 23] to improve the classification performance in cases of non-dispersive channels and one-dominant-path channels. In literature, a tree-structured modulation classification scheme [24, 25] based on three normalized fourth-order cumulants is also used for the same work.

In this paper, HOS was used for the modulation classification purpose; eleven eighthorder cumulants have been used throughout the research. The features are extracted for the noisy (AWGN) signals. The modulation schemes used here are BPSK, QPSK, QAM, 16QAM, 64QAM for a KNN classifier with different distance measurement methods i.e. Euclidean distance, Correlation distance, Minkowski distance, and Mahalanobis distance.

The rest of the paper is organized as follows: Section 2 describes the system model and Feature Extraction. Section 3 explains the classification methodology.Section 4 gives 
a comparative analysis of the KNN classifier for five modulations using different distance methods under different SNRs. Conclusion and future work is presented in section 5.

\section{SIGNAL MODEL AND FEATURE EXTRACTION}

\subsection{Signal Model}

An AWGN channel was used for these simulations. Thus, the received signal is only impaired by additive white Gaussian noise. Figure 1 shows the system model. The generalized expression for signal received is given by [26].

$$
r(n)=s(n)+y(n)
$$

where $r(n)$ complex baseband is the envelope of the received signal, $y(n)$ is the additive white gaussian noise and received signal $s(n)$ is given by

$$
s(n)=K e^{i\left(2 \pi f_{o} n T+\theta_{n}\right)} \sum_{j=-\infty}^{\infty} s(j) h\left(n T-j T+\epsilon_{T} T\right)
$$

where, $s(j)$ is the input symbol sequence which is drawn from the set of $M$ constellations of known symbols, not necessarily equi-probable. $K$ is the amplitude of the signal, $f_{o}$ is the frequency offset constant, $T$ is the symbol spacing, $\theta_{n}$ is the phase jitter which varies from symbol to symbol, $h(\ldots)$ represents channel effects, and $\epsilon_{T}$ is the timing jitter.

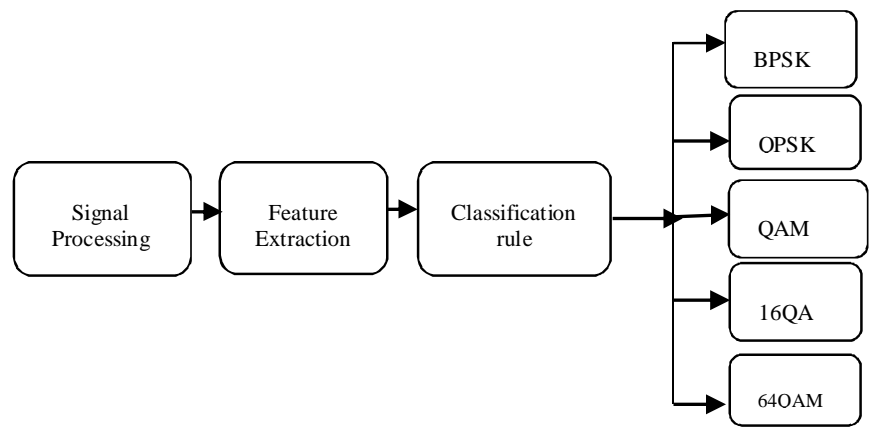

Fig. 1: System model for modulation classification.

\subsection{Feature Extraction}

Cumulants are made up of moments which are used here as features. For the complex valued stationary random process $r(n)$, cumulants of the $2 \mathrm{nd}, 4$ th, 6 th and 8 th order are as follows[27]:-

$$
\begin{aligned}
& C_{20}=E\left[y^{2}(n)\right]=\operatorname{cum}\{y(n), y(n)\} \\
& C_{21}=E\left[|y(n)|^{2}\right]=\operatorname{cum}\left\{y(n), y^{*}(n)\right\} \\
& C_{40}=M_{40}-3 M_{20}{ }^{2}=\operatorname{cum}\{y(n), y(n), y(n), y(n)\} \\
& C_{41}=M_{40}-3 M_{20} M_{21}=\operatorname{cum}\left\{y(n), y(n), y(n), y^{*}(n)\right\} \\
& C_{42}=M_{42}-\left|M_{20}\right|^{2}-2 M_{21}=\operatorname{cum}\left\{y(n), y(n), y^{*}(n), y^{*}(n)\right\} \\
& C_{60}=M_{60}-15 M_{20} M_{40}+30 M_{20}{ }^{3}=\operatorname{cum}\{y(n), y(n), y(n), y(n), y(n), y(n)\} \\
& C_{61}=M_{61}-5 M_{21} M_{40}-10 M_{20} M_{41}+30 M_{20}{ }^{2} M_{21}
\end{aligned}
$$




$$
\begin{gathered}
=\operatorname{cum}\left\{y(n), y(n), y(n), y(n), y(n), y^{*}(n)\right\} \\
C_{62}=M_{62}-6 M_{20} M_{42}-8 M_{21} M_{41}-M_{22} M_{40}+6 M_{20}{ }^{2} M_{22}+24 M_{21}{ }^{2} M_{22} \\
=\operatorname{cum}\left\{y(n), y(n), y(n), y(n), y^{*}(n), y^{*}(n)\right\} \\
C_{63}=M_{63}-9 M_{21} M_{42}+12 M_{21}{ }^{3}-3 M_{20} M_{43}-3 M_{22} M_{41}+18 M_{20} M_{21} M_{22} \\
=\operatorname{cum}\left\{y(n), y(n), y(n), y^{*}(n), y^{*}(n), y^{*}(n)\right\} \\
C_{80}=M_{80}-35 M_{40}{ }^{2}-28 M_{60} M_{20}+420 M_{40} M_{20}{ }^{2}-630 M_{20}{ }^{4} \\
=\operatorname{cum}\{y(n), y(n), y(n), y(n), y(n), y(n), y(n), y(n)\} \\
C_{84}=M_{84}-16 C_{63} C_{21}+\left|C_{40}\right|^{2}-18 C_{42}{ }^{2}-72 C_{42} C_{21}{ }^{2}-24 C_{21}{ }^{4} \\
=\operatorname{cum}\left\{y(n), y(n), y(n), y(n), y^{*}(n), y^{*}(n), y^{*}(n), y^{*}(n)\right\}
\end{gathered}
$$

$\mathrm{M}_{\mathrm{pq}}$ Stands for moments of received signal and it is given by

$$
\mathrm{M}_{\mathrm{pq}}=\mathrm{E}\left[\mathrm{y}(\mathrm{k})^{\left.\mathrm{p}-\mathrm{q}_{\mathrm{y}}{ }^{*}(\mathrm{k})^{\mathrm{q}}\right]}\right.
$$

The above cumulants are used to classify the BPSK, QPSK, QAM, 16QAM and 64QAM modulated signals in the presence of AWGN noise.

\section{KNN CLASSIFIER}

\subsection{Introduction to KNN Classifier}

KNN is a non parametric, slow adapting, and lazy algorithm in the sense that it does not make any assumptions on the underlying data distribution and requires more computations and memory. However, due to the non parametricness, KNN is well suited to practical real world problems as much of the acquired data does not agree with assumptions made in theory for mathematical convenience. This resembles the philosphy of SVM where non-support vectors can be omitted without sacrificing performance. KNN works with a minimal training phase, however, testing is performed over the whole testing data which requires more memory for its storage.

\subsection{KNN Classifiers}

The KNN classifier is used to compare the accuracy of extracted features from different modulation schemes. The eleven features are the Cumulants which have been extracted from the signal earlier. The method is quite simple. Firstly, a few values are used as sample data for the KNN classifier as there are eleven Cumulants and therefore eleven dimensional spaces for KNN. After this, some test values of these features are given to the KNN classifier and KNN calculates the distance of these samples from K neighbors' samples. The class having the maximum numbers of neighbors is considered to be the class of the test sample.

\subsubsection{Euclidean Distance}

$$
d=\sqrt{\sum_{i=1}^{11}\left(x_{i}^{s}-y_{i}^{t}\right)\left(x^{s}{ }_{i}-y^{t}{ }_{i}\right)^{\prime}}
$$

where $x_{i}^{s}$ the $\mathrm{i}^{\text {th }}$ input is feature value and $y_{i}^{t}$ is the test feature value. 


\subsubsection{Correlation Distance}

$$
d=\sum_{i=1}^{11} 1-\frac{\left(x_{i}^{s}-\overline{x_{i}^{s}}\right)\left(y_{i}^{t}-\overline{y_{i}^{t}}\right)}{\sqrt{\left(x_{i}^{s}-\overline{x_{i}^{s}}\right)\left(x_{i}^{s}-\overline{x_{i}^{s}}\right)^{\prime}} \sqrt{\left(y_{i}^{t}-\overline{y_{i}^{t}}\right)\left(y_{i}^{t}-\overline{y_{i}^{t}}\right)^{\prime}}}
$$

where $x_{i}^{s}$ is the ith input feature value and $y_{i}^{t}$ is the test feature value and furthermore,

$$
\overline{x_{i}^{s}}=\frac{1}{n} \sum_{j} x_{s j} \text { and } \overline{y_{i}^{s}}=\frac{1}{n} \sum_{j} y_{s j}
$$

\subsubsection{Mahalanobis Distance}

$$
d=\sqrt{\sum_{i=1}^{11}\left(x_{i}^{s}-y_{i}{ }^{t}\right) C^{-1}\left(x^{s}{ }_{i}-y_{i}^{t}\right)}
$$

where $x_{i}^{s}$ is the $\mathrm{i}^{\text {th }}$ input feature value and $y_{i}{ }^{t}$ is the test feature value and $\mathrm{C}$ is the covariance matrix.

\subsubsection{Minkowski Distance}

$$
d=\sqrt[p]{\sum_{j=1}^{11}\left|x_{s j}-y_{t j}\right|^{p}}
$$

where $x_{i}^{s}$ the $\mathrm{i}^{\text {th }}$ input is feature value and $y_{i}^{t}$ is the test feature value.

\section{SIMULATION RESULTS}

The modulation classification using KNN is evaluated in this section. Firstly, the input data -extracted features from the received signal and desired output signals- are used to make the classifier model, after which different distance techniques are used to classify the input signals. The performance using different distance measurement techniques for KNN under the influence of SNR and number of samples are given in the tables. Overall, 250 data samples were used at the training phase and 25 were used as test samples during the testing phase, in order to obtain the results shown in the table. The end result is an average of 10 iterations for each horizontal and vertical entryin the table.

\subsection{KNN with Euclidean Distance}

Table 1 compares the performance of the KNN classifier using Euclidean distance for digital modulations which are BPSK, QPSK, QAM, 16QAM and 64QAM with different number of samples. As can be seenin the table, the accuracy is enhanced with the increase of signal to noise ratio and number of samples. The performance accuracy for BPSK is $98.87 \%$. Similarly,the performance accuracy table for QPSK demonstrates a classification accuracy of $99.73 \%$. However, for the next modulation scheme, which is QAM, the performance accuracy is $96.80 \%$ and for 16QAM it is $99.70 \%$.At last, the classification accuracy for 64QAM is found to be $99.57 \%$. 
Table 2: Percentage classification accuracy using KNN (Euclidean distance)

\begin{tabular}{ccccc}
\hline SIGNAL & No of SAMPLE & 0dB & 5dB & 10dB \\
\hline BPSK & 512 & 88.08 & 98.97 & 100 \\
& 1024 & 98.49 & 99.98 & 100 \\
& 2048 & 99.95 & 100 & 100 \\
QPSK & 4096 & 100 & 100 & 100 \\
& 512 & 95.85 & 100 & 100 \\
& 1024 & 99.97 & 100 & 100 \\
& 2048 & 100 & 100 & 100 \\
QAM & 4096 & 100 & 100 & 100 \\
& 512 & 76 & 98 & 100 \\
& 1024 & 90.64 & 99.96 & 100 \\
& 2048 & 97.2 & 100 & 100 \\
16QAM & 4096 & 99.88 & 100 & 100 \\
& 512 & 97.87 & 99.41 & 99.73 \\
& 1024 & 99.89 & 99.99 & 100 \\
& 2048 & 100 & 100 & 100 \\
& 4096 & 100 & 100 & 100 \\
& 512 & 97.00 & 98.9 & 99.47 \\
& 1024 & 99 & 99.98 & 99.72 \\
& 2048 & 100 & 100 & 100 \\
& 4096 & 100 & 100 & 100 \\
\hline
\end{tabular}

Table 2: Percentage classification accuracy using KNN (Correlation distance)

\begin{tabular}{ccccc}
\hline SIGNAL & No of SAMPLE & OdB & $\mathbf{5 d B}$ & 10dB \\
\hline BPSK & 512 & 93.95 & 99.99 & 100 \\
& 1024 & 99.8 & 100 & 100 \\
& 2048 & 98.29 & 100 & 100 \\
QPSK & 4096 & 99.95 & 100 & 100 \\
& 512 & 94.5 & 99.3 & 100 \\
& 1024 & 94.58 & 99.68 & 100 \\
& 2048 & 95.26 & 99.70 & 100 \\
QAM & 4096 & 96.35 & 99.79 & 100 \\
& 512 & 60.23 & 73.5 & 97 \\
& 1024 & 71.92 & 82.19 & 97.99 \\
& 2048 & 80.27 & 93.3 & 99.91 \\
16QAM & 4096 & 87.05 & 93.57 & 100 \\
& 512 & 80.33 & 90.3 & 93 \\
& 1024 & 81.59 & 87.07 & 95.5 \\
& 2048 & 83.24 & 92.45 & 96.73 \\
& 4096 & 93.23 & 97.86 & 100 \\
& 512 & 80.33 & 93.65 & 95 \\
& 1024 & 87.94 & 94.98 & 96.39 \\
& 2048 & 89.93 & 96.91 & 98.17 \\
& 4096 & 90.43 & 97.83 & 100 \\
\hline
\end{tabular}

\subsection{KNN with Correlation Distance}

Table 2 compares the performance of the KNN classifier using correlation distance for digital modulations which are BPSK, QPSK, QAM, 16QAM and 64QAM with different number of samples.As can be seenin the table, the accuracy is enhanced with the 
increase of signal to noise ratio and number of samples. The performance accuracy for BPSK is $98.33 \%$.Similarly, the performance accuracy table demonstrates that the classification accuracy for QPSK is $67.53 \%$. However, for the next modulation scheme, which is QAM, the performance accuracy is $71.11 \%$ and the accuracy for 16QAM is 41.29 $\%$. At last, the classification accuracy for 64QAM is found to be $41.17 \%$.

\subsection{KNN with Minkowski Distance}

Table 3 compares the performance of the KNN classifier using Minkowski distance for digital modulations which are BPSK, QPSK, QAM, 16QAM and 64QAM with different numbers of samples. As can be seenin the table, the accuracy is enhanced with the increase of signal to noise ratio and number of samples.The performance accuracy for BPSK is $99.53 \%$.Similarly, the performance accuracy table demonstrates that for QPSK, the classification accuracy is $99.95 \%$. However, for the next modulation scheme, which is QAM, the performance accuracy is $99.38 \%$ and for 16QAM it is also $99.79 \%$.At last, the classification accuracy for 64QAM is found to be $99.63 \%$ which is same as QPSK, QAM and 64QAM.

Table 3: Percentage classification accuracy using KNN (Minkowski distance)

\begin{tabular}{ccccc}
\hline SIGNAL & No of SAMPLE & 0dB & 5dB & 10dB \\
\hline BPSK & 512 & 95.2 & 100 & 100 \\
& 1024 & 99.23 & 100 & 100 \\
& 2048 & 100 & 100 & 100 \\
QPSK & 4096 & 100 & 100 & 100 \\
& 512 & 96.4 & 99.8 & 100 \\
& 1024 & 99.98 & 100 & 100 \\
& 2048 & 100 & 100 & 100 \\
QAM & 4096 & 100 & 100 & 100 \\
& 512 & 79.96 & 99.28 & 100 \\
& 1024 & 90.62 & 99.93 & 100 \\
& 2048 & 98.91 & 100 & 100 \\
16QAM & 4096 & 99.92 & 100 & 100 \\
& 512 & 98.63 & 99.48 & 99.53 \\
& 1024 & 99.95 & 100 & 100 \\
& 2048 & 100 & 100 & 100 \\
& 4096 & 100 & 100 & 100 \\
& 512 & 97.33 & 99.78 & 100 \\
& 1024 & 99.95 & 99.96 & 100 \\
& 2048 & 97.2 & 100 & 100 \\
& 4096 & 99.88 & 100 & 100 \\
\hline
\end{tabular}

\subsection{KNN with Mahalanobis Distance}

Table 4 compares the performance of the KNN classifier using Mahalanobis distance for digital modulations which are BPSK, QPSK, QAM, 16QAM and 64QAM with different numbers of samples. As can be seenin the table,the accuracy is enhanced with the increase of signal to noise ratio and number of samples. The performance accuracy for BPSK is $99.95 \%$. Similarly, the performance accuracy table demonstrates that the classification accuracy is $99.97 \%$ for QPSK. However, for the next modulation scheme, which is QAM, the performance accuracy is $99.97 \%$ and for 16QAM it is also $99.91 \%$. At last, the classification accuracy for 64QAM is found to be $99.87 \%$. 
Table 4: Percentage classification accuracy using KNN (Mahalanobis distance)

\begin{tabular}{ccccc}
\hline SIGNAL & No of SAMPLE & 0dB & 5dB & 10dB \\
\hline BPSK & 512 & 97.56 & 99.96 & 100 \\
& 1024 & 99.80 & 100 & 100 \\
& 2048 & 99.92 & 100 & 100 \\
QPSK & 4096 & 100 & 100 & 100 \\
& 512 & 97.84 & 99.92 & 99.96 \\
& 1024 & 99.92 & 100 & 100 \\
& 2048 & 100 & 100 & 100 \\
QAM & 4096 & 100 & 100 & 100 \\
& 512 & 99.68 & 99.84 & 100 \\
& 1024 & 99.76 & 99.84 & 100 \\
& 2048 & 99.96 & 99.80 & 100 \\
16QAM & 4096 & 100 & 100 & 100 \\
& 512 & 98.63 & 99.92 & 100 \\
& 1024 & 99.88 & 99.88 & 99.92 \\
& 2048 & 99.80 & 99.92 & 99.96 \\
& 4096 & 100 & 100 & 100 \\
& 512 & 97.84 & 99.88 & 100 \\
& 1024 & 99.88 & 99.88 & 99.88 \\
& 2048 & 99.84 & 99.92 & 99.92 \\
& 4096 & 99.80 & 99.92 & 99.88 \\
\hline
\end{tabular}

\subsection{Average Classification Performance}

Table 5 shows the overall performance accuracy of each modulated signal with different distance measurement method for the KNN classifier. Each column represents the distance measurement technique and rows show the modulation scheme which was used in this paper. The performance of KNN with Euclidean distance was excellent for almost every modulation technique used. A $98.87 \%$ performance accuracy was achieved in the case of BPSK, and for QPSK it was 99.73\%. QAM showed $96.80 \%$ performance accuracy, for 16QAM it was $99.70 \%$, and for 64QAM performance accuracy was $99.57 \%$. However, the correlation distance showed moderate results in comparison to other distance methods used. In the case of BPSK, a 99.33\% accuracy was obtained.For 16QAM,the accuracy was 90.94\%.Moreover, QPSK,QAM, and 64 QAM obtained $98.26 \%, 86.41 \%$, and $93.46 \%$ respectively.KNN with Minkowski distance gave excellent results in all means; which is evident from the above table. 64QAM was classified with an accuracy of 99.63\% and BPSK, QPSK, QAM, and 16QAM showedaccuracies of 99.53\%, 99.95\%, 99.38\%, and 99.79\% respectively. The Mahalanobis distance with KNN also showed very good results, 64QAM had a low performance of $99.87 \%$, while QPSK and QAM had maximum performance with $99.97 \%$.

Table 5: Average Classification performance accuracy for KNN with used distance measurement approaches

\begin{tabular}{crccc} 
Modulation Type & Euclidean & Correlation & Minkowski & Mahalanobis \\
\hline BPSK & $98.87 \%$ & $99.33 \%$ & $99.53 \%$, & $99.95 \%$ \\
QPSK & $99.73 \%$ & $98.26 \%$. & $99.95 \%$. & $99.97 \%$. \\
QAM & $96.80 \%$ & $86.41 \%$ & $99.38 \%$ & $99.97 \%$ \\
16QAM & $99.70 \%$ & $90.94 \%$ & $99.79 \%$. & $99.91 \%$. \\
64QAM & $99.57 \%$ & $93.46 \%$. & $99.63 \%$ & $99.87 \%$.
\end{tabular}




\subsection{Comparison of Classification Accuracy with Different Distance Methods}

This subsection presents the comparison of percentage of classification accuracy versus different SNR values under different distance methods. Due to limitations of space, graphs are presented in Fig. 2 to Fig. 6 for all 512 samples for the cases of BPSK, QPSK, QAM, 16 QAM and 64 QAM modulation schemes.

It can be clearly observed that the Mahalanobis distance method produces higher classification accuracy percentage compared to Euclidean, Correlation, and Minkowski distance methods for all modulation schemes under consideration. The correlation distance method is shown to have performed poorly compared to all other distance methods for all schemes other than BPSK. In the case of a BPSK modulation scheme,the correlation distance method out-performed the Euclidean distance method. However, overall the correlation method is shown to be the least performing of all distance methods.

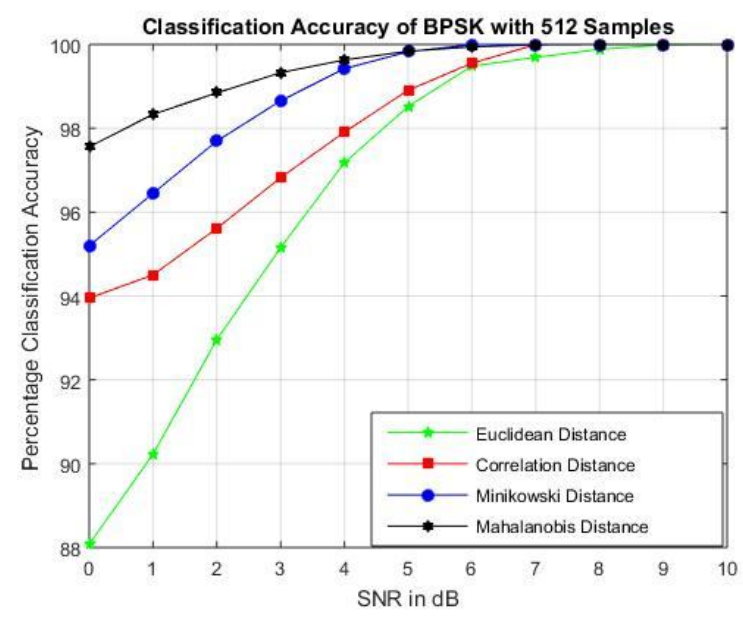

Fig. 2: Classification accuracy of BPSK modulation scheme for 512 samples with different SNR and distance methods.

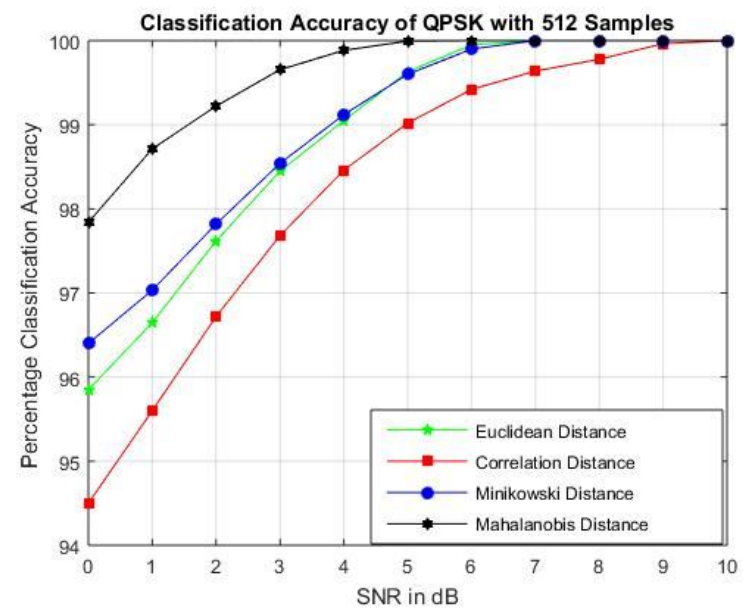

Fig. 3: Classification accuracy of QPSK modulation scheme for 512 samples with different SNR and distance methods. 


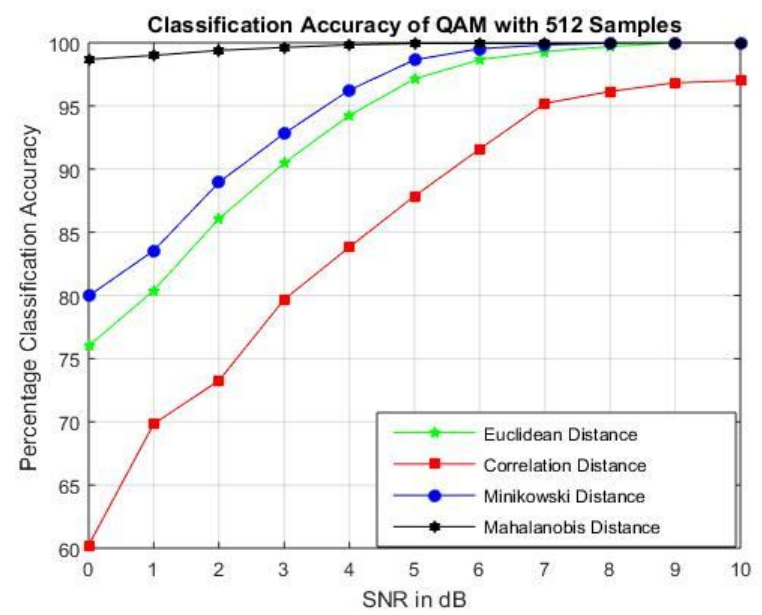

Fig. 4: Classification accuracy of QAMmodulation scheme for 512 samples with different SNR and distance methods.

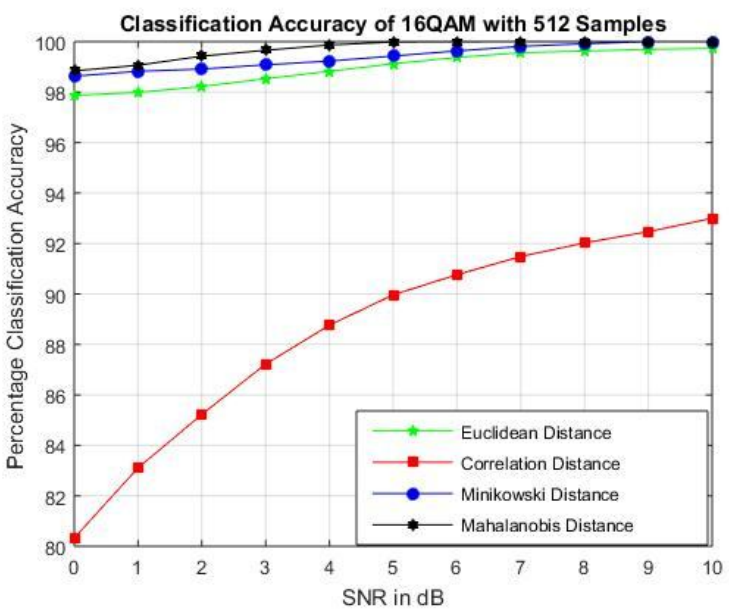

Fig. 5: Classification accuracy of 16QAMmodulation scheme for 512 samples with different SNR and distance methods.

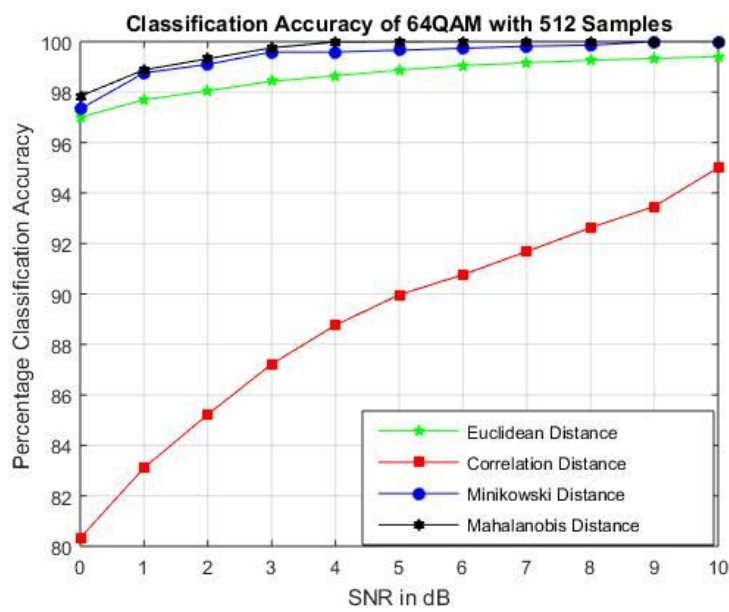

Fig. 6: Classification accuracy of 64QAMmodulation scheme for 512 samples with different SNR and distance methods. 


\section{CONCLUSION AND FUTURE WORK}

In this paper, a classifier was proposed based on KNN using different distance methods on the sample data, in which HOC was used to extract features from the received signal under influence of SNR combined with an AWGN channel. Eleven eighth-order features were used for five different modulation schemes, namely BPSK, QPSK, QAM, 16QAM and 64QAM to be classified. Average performance accuracy was calculated with different SNR and number of samples which showed that the Mahalanobis distance method had a slight edge over the Minkowski method in terms of accuracy. Euclidean distance-based KNN classifier fell behind the aforementioned two distance methods classifiers. Correlation distance gave the least performance accuracy, making it unusable for classification.

In future, normalized cumulants can be used for feature extraction and GP for the new sample data generation with $\mathrm{KNN}$ as a fitness evaluator to improve the performance accuracy. Different channels and different modulation schemescan be used for the same problem.

\section{REFERENCES}

[1] Ghauri SA, Qureshi IM, Malik AN, Cheema TA. (2014) A novel modulation classification approach using gabor filter network. The Scientific World Journal, 2014:1-14.

[2] Xu J, Su W, Zhou M. (2011) Likelihood-ratio approaches to automatic modulation classification. IEEE Trans. Syst. Man Cybern. C, Appl. Rev., 41(4):455-469

[3] Ghauri SA, Qureshi IM. (2015). M-PAM signals classification using modified Gabor filter network. Mathematical Problems in Engineering. volume 2015:1-10

[4] Ghauri SA, Qureshi IM, Shah I, Khan N. (2014) Modulation classification using cyclostationary features on fading channels. Res. J. App. Sci. Eng. Tech., 7(24):5331-5339.

[5] Azzouz EE, Nandi AK. (1998) Algorithms for automatic modulation recognition of communication signals. IEEE Trans. Commun., 46(4):431-436.

[6] Wang F, Wang X. (2010) Fast and robust modulation classification via KolmogorovSmirnov test. IEEE Trans. Commun., 58(8):2324-2332.

[7] Ho KC, Prokopiw W, Chan YT. (2000) Modulation identification of digital signals by the wavelet transform. IEE Proc. Radar Sonar Navig., 147(4):169-176.

[8] Hong L, Ho K. (1999) Identification of digital modulation types using the wavelet transform. IEEE Military Communications Conf. Proceedings:427-431

[9] Zhao F, Hu Y, Hao S. (2008) Classification using wavelet packet decomposition and support vector machine for digital modulations. J. Syst. Eng. Electron., 19(5):914-918.

[10] Li P, Wang F, Wang Z.(2006) Algorithm for modulation recognition based on high-order cumulants and subspace decomposition. in proceeding of ICSP 2006,vienna (Austria).

[11] Mirarab M, Sobhani M. (2007) Robust modulation classification for PSK/QAM/ASK using higher-order cumulants. Sixth Int. Conf. on Information, Communications and Signal Processing Proceedings: $1-4$

[12] Shen L, Li S, Song S, Chen F. (2006) Automatic modulation classification of MPSK signals using high order cumulants. Eighth Int. Conf. on Signal Processing Proceedings. 1-4

[13] An N, Li B, Huang M. (2010) Modulation classification of higher order MQAM signals using mixed-order moments and Fisher criterion. Second Int. Conf. on Computer and Automation Engineering Proceedings:150-153

[14] Shan Z, Xin Z, Ying W. (2010) Improved modulation classification of MPSK signals based on high order cumulants. 2nd Int. Conf. on Future Computer and Communication Proceedings: 444-448

[15] Swami A, Sadler B. (2000) Hierarchical digital modulation classification using cumulants. IEEE Trans. Commun., 48(3):416-429. 
[16] Han G, Li J, Chen C. (2003) A robust MDPSK modulation classifier based on cumulants. 17th Int. Conf. on Advanced Information Networking and Applications proceedings:265269.

[17] Pedzisz M, Mansour A. (2005) Automatic modulation recognition of MPSK signals using constellation rotation and its 4th order cumulant. Digital Signal Process., 15(3):295-304.

[18] Yang L, Ji Z, Xu X, Dai X, Xu P. (2007) Modulation classification in multipath fading environments. Fourth Int. Symp. on Wireless Communication Systems proceedings, :171174.

[19] Wu HC, Saquib M, Yun Z. (2008) Novel automatic modulation classification using cumulant features for communications via multipath channels. IEEE Trans. Wirel. Commun., 7(8):3098-3105.

[20] Ramkumar B, Bose T, Radenkovic MS. (2010) Robust multiuser automatic modulation classifier for multipath fading channels. IEEE Symp. on New Frontiers in Dynamic Spectrum proceedings, 1-10.

[21] Orlic V, Dukic M. (2009) Algorithm for automatic modulation classification in multipath channel based on sixth-order cumulants. Ninth Int. Conf. on Telecommunication in Modern Satellite, Cable and Broadcasting Services proceedings, 423-426.

[22] Orlic V, Dukic ML. (2010) Multipath channel estimation algorithm for automatic modulation classification using sixth-order cumulants. Electron. Lett., 1348-1349.

[23] Park C, Kim D. (2006) A novel robust feature of modulation classification for reconfigurable software radio. IEEE Trans. Consum. Electron., 52(4):1193-1200.

[24] Nikias CL, Petropuou A. (1993) Higher-order spectral analysis. Prentice Hall, Englewood Cliffs NJ.

[25] Stark H, Woods JW. (2002) Probability and random processes with applications to signal processing, 3rd ed. Prentice Hall, Upper Saddle River, NJ

[26] Ghauri SA, Qureshi IM, Aziz A, Cheema TA. (2014) Classification of digital modulated signals using linear discriminant analysis on faded channel. World App. Sci. J., 29(10):1220-1227.

[27] Ghauri SA, Qureshi IM, Malik AN, Cheema TA. (2014) Automatic digital modulation classification technique using higher order cummulants on faded channels. J. Basic. Appl. Sci. Res., 4(3):1-12. 